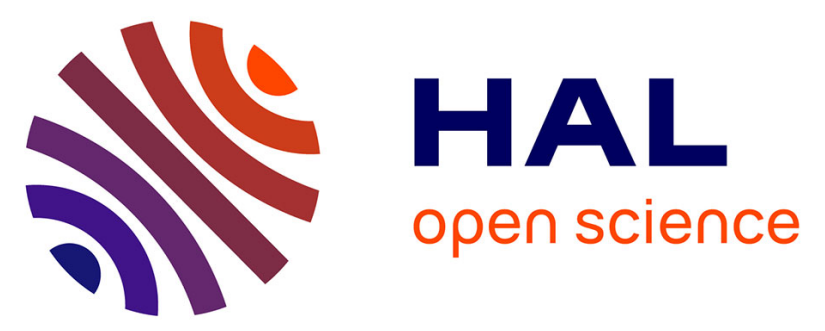

\title{
Contribution of Fourier-domain optical coherence tomography to the diagnosis of keratoconus progression
}

\author{
Sofiane Ouanezar, Otman Sandali, Raphael Atia, Cyrille Temstet, Cristina
}

Georgeon, Laurent Laroche, Vincent Borderie, Nacim Bouheraoua

\section{To cite this version:}

Sofiane Ouanezar, Otman Sandali, Raphael Atia, Cyrille Temstet, Cristina Georgeon, et al.. Contribution of Fourier-domain optical coherence tomography to the diagnosis of keratoconus progression. Journal of Cataract and Refractive Surgery, 2019, 45, pp.159 - 166. 10.1016/j.jcrs.2018.09.024 . hal03486073

\section{HAL Id: hal-03486073 \\ https://hal.science/hal-03486073}

Submitted on 20 Dec 2021

HAL is a multi-disciplinary open access archive for the deposit and dissemination of scientific research documents, whether they are published or not. The documents may come from teaching and research institutions in France or abroad, or from public or private research centers.
L'archive ouverte pluridisciplinaire HAL, est destinée au dépôt et à la diffusion de documents scientifiques de niveau recherche, publiés ou non, émanant des établissements d'enseignement et de recherche français ou étrangers, des laboratoires publics ou privés.

\section{(ㅇ)(1) $\$$}

Distributed under a Creative Commons Attribution - NonCommercial| 4.0 International 


\title{
Contribution of Fourier-domain optical coherence tomography to the diagnosis of keratoconus progression
}

\author{
Sofiane Ouanezar, MD, Otman Sandali, MD, Raphael Atia, MD, Cyrille Temstet, MD, Cristina Georgeon, MS, \\ Laurent Laroche, MD, Vincent Borderie, MD, PhD, Nacim Bouheraoua, MD, PhD
}

Purpose: To determine the anatomic criteria for diagnosing keratoconus progression by corneal optical coherence tomography (OCT).

Setting: Quinze-Vingts National Ophthalmology Hospital, Paris, France.

Design: Prospective case series.

Methods: Scanning-slit corneal topography (Orbscan II) and Fourier-domain corneal OCT (RTVue) were performed in eyes with mild to moderate keratoconus (progressive or nonprogressive [stable] ectasia) at each examination to assess the keratoconus. Disease progression was defined as an increase of at least 1.0 diopter $(\mathrm{D})$ in the steepest keratometry $(\mathrm{K})$ measurement over 6 months.

Results: Of the 134 eyes of 134 patients with mild to moderate keratoconus, 98 had had progressive ectasia and 36 nonprogressive ectasia. The mean maximum $\mathrm{K}$ increased significantly in the progressive group $(2.1 \mathrm{D} \pm 1.2[\mathrm{SD}], P<.0001)$ and remained constant in the stable group $(-0.03 \pm 0.39 \mathrm{D}, P=.31)$. The mean thinnest corneal thickness increased significantly in the progressive group $(-7.98 \pm 9.3 \mu \mathrm{m}, P<.0001)$ and remained constant in the stable group $(-0.52 \pm 4.21 \mu \mathrm{m}, P=.22)$. The change in maximum $\mathrm{K}$ was significantly correlated with changes in the thinnest corneal thickness $(r=-0.61, P<.0001)$. A cutoff value of $-5 \mu \mathrm{m}$ for the change in thinnest corneal thickness was identified on receiver operating characteristic curves as a threshold separating cases of progressive and stable keratoconus (area under the curve, 0.79; sensitivity, 68\%; specificity, 89\%).

Conclusions: Topographic data partly reflected the structura changes occurring during the progression of corneal ectasia. Based on the pachymetric parameters provided by OCT, corneal and epithelial thinning was correlated with corneal deformation. The use of corneal OCT might therefore improve the diagnostic sensitivity for keratoconus progression.

J Cataract Refract Surg 2019; 45:159-166 ๔ 2018 ASCRS and ESCRS
K eratoconus is the most common primary ectatic corneal disorder. Its prevalence has been estimated at 1 case per 375 individuals. ${ }^{1}$ It is characterized by progressive corneal thinning, irregular astigmatism, and vision loss. Histological changes include stromal thinning, a decrease in keratocyte density, Bowman layer disruption, splitting in the cone region, and epithelial changes. ${ }^{2,3} \mathrm{We}$ recently used Fourier-domain optical coherence tomography (OCT) to study these changes and established a new anatomic classification of keratoconus based on the architectural modifications visible on OCT during ectasia progression. ${ }^{4}$

In general, keratoconus becomes apparent during puberty, progresses until the patient's $30 \mathrm{~s}$, and stabilizes thereafter. ${ }^{5}$ Several factors, such as changes in irregular astigmatism or corneal aberrations, changes in inferior corneal steepening, changes in apex location, and a posterior steepening, have been found to be associated with keratoconus progression. Clinical factors associated with progression include a decrease in visual acuity, young age at presentation, severe eye rubbing, and the occurrence of corneal scarring. Corneal crosslinking (CXL) has been shown to slow keratoconus progression in mild to moderate cases, improving visual outcomes and reducing or delaying the need for corneal transplantation. ${ }^{6,7}$

However, the established criteria for keratoconus progression are based principally on topographic features and do not take into account anatomic changes in the

Submitted: January 29, 2018 | Final revision submitted: August 30, 2018 | Accepted: September 7, 2018

From Quinze-Vingts National Ophthalmology Hospital (Ouanezar, Sandali, Atia, Temstet, Georgeon, Laroche, Borderie, Bouheraoua) and the Institut de la Vision (Laroche, Borderie, Bouheraoua), Institut National de la Santé et de la Recherche Médicale UMR S968, UPMC-Sorbonne Université, Paris, France.

Corresponding author: Nacim Bouheraoua, MD, PhD, Quinze-Vingts National Ophthalmology Hospital, UPMC-Sorbonne Université, 28 , rue de Charenton, 75012 Paris, France. Email: nacim.bouheraoua@gmail.com.

(C) 2018 published by Elsevier. This manuscript is made available under the CC BY NC user license https://creativecommons.org/licenses/by-nc/4.0/ 
cornea, including those affecting the corneal layers during keratoconus progression. ${ }^{8-13}$ Furthermore, these criteria differ considerably between CXL studies. For example, progression might be assessed at 6- or 12-month intervals, and keratometry can be performed with different tools and methods that have different sensitivities, such as autokeratometry, videotopography, Scheimpflug imaging, and, more recently, OCT topography. The recent global consensus on corneal ectasia was that there is still no definitive definition of disease progression. ${ }^{14}$ The repeatability of corneal curvature measurements is also significantly lower in patients with keratoconus as a result of surface irregularity, greater curvature, and the presence of corneal scarring. ${ }^{15-19}$

The purpose of this study was to define new anatomic criteria, based on corneal OCT, for progressive keratoconus in a large population of patients.

\section{PATIENTS AND METHODS}

This prospective observational nonrandomized clinical study was performed at Quinze-Vingts National Ophthalmology Hospital, Paris, France. Informed consent was obtained from each patient before inclusion in the study according to the tenets of the Declaration of Helsinki, and the study was approved by the Ethics Committee of the French Society of Ophthalmology (Institutional Review Board 00008855).

Data on consecutive cases of progressive keratoconus followed from January 2014 to January 2016 were collected and prospectively analyzed. All patients had a complete ocular examination. The criteria for keratoconus diagnosis were the presence of central corneal thinning, conical protrusion, Vogt striae, or Fleisher ring on slitlamp examination and a keratoconic appearance on topographic maps.

Patients were examined every 6 months. Keratoconus progression was defined as an increase of at least 1.0 diopter (D) in the steepest keratometry $(\mathrm{K})$ measurement over a period of 6 months. At the end of the examination, patients defined as evolving benefited from CXL. Criteria relating to a loss of visual acuity and changes in subjective refraction were not taken into account because their evaluation was not reliable..$^{20,21}$

The inclusion criteria were mild to moderate keratoconus (stage 1 to 3 according to the Amsler-Krumeich classification ${ }^{22}$ ) with a minimum corneal thickness greater than $380 \mu \mathrm{m}$, compatible with treatment by CXL. To avoid bias, if both eyes of a patient were eligible, only the right eye was included. The exclusion criteria were any type of previous ocular surgery, including CXL, corneal rings, or keratoplasty. Contact lens wearers were instructed to discontinue their use at least 2 weeks before the examination to avoid false $\mathrm{K}$ and pachymetric values. ${ }^{23,24}$

This study used a Fourier-domain OCT system (RTVue, Optovue, Inc.) with a corneal adaptor module. This system works at a wavelength of $830 \mathrm{~nm}$ and has a scan speed of 26000 axial scans per second and a depth resolution of $5 \mu \mathrm{m}$ in tissue.

Corneal epithelial and stromal thicknesses were defined as the distances between the air-tear and the epithelium-Bowman layer interfaces and between the Bowman layer-stroma and stromaDescemet membrane interfaces, respectively. The keratoconus cone was located at the thinnest point according to pachymetry.

A pachymetry scan pattern $(6.0 \mathrm{~mm}$ scan diameter, 8 radials, 1024 axial scans, each repeated 5 times) centered on the center of the pupil was used to map the cornea. The corneal adaptor module software (version 5.5) automatically processed the OCT scan to provide the pachymetry corneal thickness map and the epithelial thickness map. The following corneal thickness parameters were recorded: thinnest corneal thickness and central corneal thickness
(CCT), difference between superior and inferior (S-I) mean thickness, difference between the thinnest and the thickest thicknesses, the position ( $X$ and $Y$ coordinates) of the thinnest point besides the center of the cornea. The following epithelial thickness parameters were recorded: central and thinnest epithelial thicknesses, maximum epithelial thickness, difference between the minimum and maximum thickness, mean S-I thicknesses.

Corneal topography was assessed with a scanning-slit corneal topographer (Orbscan IIz, Bausch \& Lomb Surgical, Inc.). The following topographic data were recorded: maximum $\mathrm{K}$ measurement, simulated maximum $\mathrm{K}$ measurement, minimum $\mathrm{K}$ measurement, simulated astigmatism at the center and in the paracentral 3.0 to $5.0 \mathrm{~mm}$, and mean corneal power in the paracentral 3.0 to $5.0 \mathrm{~mm}$.

At least 3 images were obtained of each examination to ensure quality of the scanning-slit corneal topographer and OCT acquisitions. The images were visually inspected, and the best was selected according to the quality of the keratoscope photographs and OCT scans.

Moreover, the repeatability of OCT and topography analyses was first assessed by having 2 experienced operators perform 3 consecutive examinations on a sample of 30 keratoconus cases in both groups. The interobserver agreement for the measurement of epithelial and stromal thickness and maximum $\mathrm{K}$ values was assessed by the intraclass correlation coefficient (ICC); the limits of agreement were assessed using the Bland-Altman method. The ICC was considered reliable if the values were between 0.4 and 0.75 ; values greater than 0.75 were considered excellent.

The results are presented as means \pm SD for continuous variables and as proportions for discrete variables. The d'AgostinoPearson test was used to assess the normal distribution of the data, after which parametric statistics were used. Student $t$ tests were used to compare initial parameters between groups and to compare parameters within and between groups. The Spearman correlation coefficient test was used to explore the relationship between values. Given the number of correlations tested, a Bonferroni correction was performed. For binary outcomes, the stratified Cochran chi-square test was used for intergroup comparisons of proportions.

Receiver operating characteristic (ROC) curve analyses were performed to evaluate the diagnostic performance of various pachymetric data. The area under the ROC curve (area under the curve [AUC]) was calculated for each variable. Interobserver agreement for the measurement of epithelial and stromal thicknesses from OCT images and for the measurement of topographic parameters with the scanning-slit corneal topographer was assessed by calculating the ICC.

Corrected $P$ values less than 0.05 were considered to be statistically significant. Statistical analysis was performed using SPSS for Windows software (version 20.0, IBM Corp.).

\section{RESULTS}

In this study, 134 eyes of 134 patients were analyzed, 98 with progressive keratoconus and 36 with nonprogressive (stable) keratoconus. Of all patients, 90 wore contact lenses. Table 1 shows the patients' demographic, topographic, and pachymetric data. The baseline characteristics in the progressive keratoconus group and in the stable keratoconus group were similar. The mean follow-up was $8.4 \pm$ 3.25 months and $7.94 \pm 3.48$ months, respectively. No significant differences in topographic or pachymetric parameters were detected between the 2 groups.

Table 2 shows the changes in topographic parameters over time by group. Table 3 shows the changes in pachymetric parameters over time by group. The mean maximum $\mathrm{K}$ variation was significant in in the progressive 
Table 1. Comparison of baseline demographic, topographic, and pachymetric data between progressive keratoconus group and nonprogressive keratoconus group.

\begin{tabular}{|c|c|c|c|}
\hline Parameter & Progressive $(n=98)$ & Nonprogressive $(n=36)$ & $P$ Value \\
\hline Mean age (y) & $27.02 \pm 6.45$ & $25.90 \pm 7.10$ & $.17^{\star}$ \\
\hline Mean follow-up (mo) & $8.4 \pm 3.25$ & $7.94 \pm 3.48$ & $.41^{\star}$ \\
\hline \multicolumn{4}{|l|}{ Amsler-Krumeich (n) } \\
\hline Stage 1 & 0 & 0 & $.9+$ \\
\hline Stage 2 & 50 & 18 & \\
\hline Stage 3 & 48 & 18 & \\
\hline Stage 4 & 0 & 0 & \\
\hline \multicolumn{4}{|l|}{ Mean K (D) } \\
\hline Maximum & $53.21 \pm 5.65$ & $52.78 \pm 5.34$ & $.72^{*}$ \\
\hline Simulated maximum & $50.02 \pm 5.38$ & $49.51 \pm 5.43$ & $.67^{\star}$ \\
\hline \multicolumn{4}{|l|}{ Mean elevation (mm) } \\
\hline Anterior & $7.69 \pm 0.35$ & $7.74 \pm 0.27$ & $.60^{*}$ \\
\hline Posterior & $6.18 \pm 0.34$ & $6.24 \pm 0.25$ & $.53^{*}$ \\
\hline \multicolumn{4}{|l|}{ Mean astigmatism (D) } \\
\hline Simulated Kmax & $4.51 \pm 2.71$ & $4 \pm 2.65$ & $.34^{*}$ \\
\hline Simulated Kmin & $45.99 \pm 4.25$ & $45.42 \pm 3.65$ & $.54^{*}$ \\
\hline \multicolumn{4}{|l|}{ Mean corneal power (D) } \\
\hline Paracentral 3-5 mm & $46.31 \pm 6.65$ & $46.85 \pm 3.02$ & $.65^{\star}$ \\
\hline Paracentral 5-7 mm & $45.18 \pm 2.49$ & $44.89 \pm 1.79$ & $.63^{*}$ \\
\hline \multicolumn{4}{|c|}{ Mean corneal thickness ( $\mu \mathrm{m})$} \\
\hline Central & $466.18 \pm 38.2$ & $457.3 \pm 38.9$ & $.22^{\star}$ \\
\hline Thinnest & $438.07 \pm 43.63$ & $431 \pm 39.7$ & $.35^{\star}$ \\
\hline Minimum-maximum & $-110.2 \pm 45.15$ & $-105.2 \pm 29.85$ & $.50^{\star}$ \\
\hline Superior-inferior & $48.35 \pm 20.76$ & $49.11 \pm 21.24$ & $.89^{*}$ \\
\hline \multicolumn{4}{|c|}{ Mean epithelial thickness $(\mu \mathrm{m})$} \\
\hline Central & $51.25 \pm 6.22$ & $49.36 \pm 5.68$ & $.16^{\star}$ \\
\hline Thinnest & $40.05 \pm 4.95$ & $40.63 \pm 6.05$ & $.70^{\star}$ \\
\hline Maximum & $64.2 \pm 7.8$ & $62.1 \pm 6.62$ & $.37^{\star}$ \\
\hline Minimum-maximum & $-27.1 \pm 10.3$ & $-21.45 \pm 8.58$ & $.19^{*}$ \\
\hline Superior & $56.57 \pm 4.74$ & $54.77 \pm 4.53$ & $.12^{*}$ \\
\hline Inferior & $50.1 \pm 5.1$ & $50.42 \pm 4.51$ & $.81^{*}$ \\
\hline
\end{tabular}

$\mathrm{K}=$ keratometry

Means \pm SD

${ }^{*}$ Student $t$ test for intergroup comparison

${ }^{\dagger}$ Chi-square test

group $(P<.0001)$ but not in in the stable group $(P=.31)$. In the progressive group, significant thinning was observed in the following parameters: CCT $(P<.0001)$, thinnest corneal thickness variation $(P<.0001)$, central epithelial thickness variation $(P=.002)$, and thinnest epithelial thickness variation $(P<.0001)$. In the stable group, no significant changes in the thicknesses measured were observed.

Changes in the topographic data obtained with the scanning-slit corneal topographer were significant in the progressive group only for the following parameters: simulated maximum $\mathrm{K}(P<.0001)$, simulated minimum $\mathrm{K}$ $(P=.007)$, and mean corneal power in the paracentral 3.0 to $5.0 \mathrm{~mm}(P<.0001)$.

Table 4 shows the correlations between the changes in each topographic and pachymetric parameter. The topographic parameter correlated with the largest number of pachymetric parameters was the maximum $\mathrm{K}$ variation. The pachymetric parameter correlated with the largest number of topographic parameters was the thinnest corneal thickness variation. Changes in the maximum $\mathrm{K}$ value were significantly correlated with changes in CCT, thinnest corneal thickness, thinnest epithelial thickness, thinnest epithelial thickness, simulated maximum $\mathrm{K}$, simulated minimum $\mathrm{K}$, and mean corneal power in the paracentral 3.0 to $5.0 \mathrm{~mm}$.

Comparison of scanning-slit corneal topography and OCT corneal and epithelial mapping repeatability showed that the OCT and keratometric images yielded highly reproducible epithelial and stromal thickness measurements. Interobserver repeatability for the maximum $\mathrm{K}$, CCT, and thinnest corneal thickness measurements by the scanning-slit corneal topographer were $0.29 \mathrm{D}(95 \%$ confidence interval [CI], 0.18-0.39), $8.6 \mu \mathrm{m}$ (95\% CI, 5.711.4), $8.6 \mu \mathrm{m}$ (95\% CI, 4.6-12.7), respectively. Interobserver repeatability for CCT, thinnest corneal thickness, central epithelial thickness, and thinnest epithelial thickness measurements by the Fourier-domain OCT were $4.8 \mu \mathrm{m}$ (95\% CI, 3.8-5.8), $2.1 \mu \mathrm{m}$ (95\% CI, 1.4-2.8), $1.9 \mu \mathrm{m}$ (95\% CI, 1.1-2.6), and $1.8 \mu \mathrm{m}$ (95\% CI, 1.0-2.6), respectively. 
Table 2. Changes in topographic parameters over time in progressive keratoconus group and nonprogressive keratoconus group.

\begin{tabular}{|c|c|c|c|c|}
\hline \multirow[b]{3}{*}{ Parameter } & \multicolumn{4}{|c|}{ Mean \pm SD } \\
\hline & \multicolumn{2}{|c|}{ Progressive $(n=98)$} & \multicolumn{2}{|c|}{ Nonprogressive $(n=36)$} \\
\hline & Variation & $P$ Value ${ }^{*}$ & Variation & $P$ Value ${ }^{*}$ \\
\hline \multicolumn{5}{|l|}{$\mathrm{K}(\mathrm{D})$} \\
\hline Maximum & $2.1 \pm 1.2$ & $<.0001^{\dagger}$ & $-0.03 \pm 0.39$ & .31 \\
\hline Simulated maximum & $1.54 \pm 2.14$ & $<.0001^{\dagger}$ & $0.11 \pm 0.55$ & .11 \\
\hline \multicolumn{5}{|l|}{ Elevation (mm) } \\
\hline Anterior & $-0.06 \pm 0.12$ & $<.0001^{\dagger}$ & $0.00 \pm 0.06$ & .41 \\
\hline Posterior & $0.03 \pm 0.2$ & $.03^{\dagger}$ & $0.01 \pm 0.10$ & .31 \\
\hline \multicolumn{5}{|l|}{ Mean astigmatism (D) } \\
\hline Simulated Kmax & $0.25 \pm 1.02$ & $.02^{+}$ & $-0.18 \pm 0.64$ & .52 \\
\hline Simulated Kmin & $0.91 \pm 2.21$ & $.007^{+}$ & $0.24 \pm 0.66$ & .18 \\
\hline \multicolumn{5}{|l|}{ Corneal power (D) } \\
\hline Paracentral 3-5 mm & $0.93 \pm 1.25$ & $<.0001^{\dagger}$ & $0.03 \pm 0.58$ & .38 \\
\hline Paracentral 5-7 mm & $0.46 \pm 1.26$ & $.002^{\dagger}$ & $0.03 \pm 0.36$ & .29 \\
\hline \multicolumn{5}{|l|}{ Astigmatism (D) } \\
\hline Paracentral 3-5 mm & $0.19 \pm 0.85$ & $.04^{+}$ & $-0.06 \pm 0.34$ & .17 \\
\hline Paracentral 5-7 mm & $0.21 \pm 0.91$ & $.02^{+}$ & $-0.01 \pm 0.62$ & .47 \\
\hline
\end{tabular}

$\mathrm{K}=$ keratometry

*Student $t$ test for within-group comparison

${ }^{+}$Statistically significant $(P<.05)$

Corneal thickness was better evaluated by OCT than by scanning-slit corneal topography. Finally, thinning of $4.2 \mu \mathrm{m}$ at the thinnest corneal thickness, measured by the Fourier-domain OCT, had more than a $95 \%$ probability of corresponding to true corneal thinning.

Considering these results, the values for which a modification of the parameter has a $95 \%$ probability of corresponding to a real change was defined. A $0.6 \mathrm{D}$ increase in the maximum $\mathrm{K}$ measurement by the scanning-slit corneal topographer has $95 \%$ of probability of reflecting posterior steepening, and a $4 \mu \mathrm{m}$ decrease of the thinnest corneal thickness measurement by the Fourier-domain OCT has $95 \%$ of probability of reflecting real corneal thinning.

Figure 1 shows the ROC curve for thinnest corneal thickness on OCT. A positive test result indicates progressive keratoconus and a negative test result indicates nonprogressive keratoconus, according to the definition given above

Table 3. Changes in pachymetric parameters over time in progressive keratoconus group and nonprogressive keratoconus group.

\begin{tabular}{|c|c|c|c|c|}
\hline \multirow[b]{3}{*}{ Parameter } & \multicolumn{4}{|c|}{ Mean \pm SD } \\
\hline & \multicolumn{2}{|c|}{ Progressive $(n=98)$} & \multicolumn{2}{|c|}{ Nonprogressive $(n=36)$} \\
\hline & Variation & $P$ Value ${ }^{*}$ & Variation & $P$ Value* \\
\hline \multicolumn{5}{|l|}{ Corneal thickness $(\mu \mathrm{m})$} \\
\hline Central & $-7.04 \pm 11.8$ & $<.0001^{\dagger}$ & $1.77 \pm 6.1$ & .06 \\
\hline Thinnest & $-7.98 \pm 9.3$ & $<.0001^{\dagger}$ & $-0.52 \pm 4.21$ & .22 \\
\hline Minimum-maximum & $5.80 \pm 18.65$ & .01 & $-0.51 \pm 19.92$ & .44 \\
\hline Superior-inferior & $-0.62 \pm 40.45$ & .36 & $0.22 \pm 10.36$ & .44 \\
\hline$X$ coordinate & $62.73 \pm 447$ & .24 & $18.15 \pm 414.32$ & .40 \\
\hline Y coordinate & $-71.54 \pm 356$ & .19 & $106 \pm 341$ & .37 \\
\hline \multicolumn{5}{|l|}{ Epithelial thickness ( $\mu \mathrm{m})$} \\
\hline Central & $-1.8 \pm 4.8$ & .002 & $-0.52 \pm 2.14$ & .08 \\
\hline Thinnest & $-1.53 \pm 2.9$ & $<.0001^{\dagger}$ & $-0.44 \pm 3.15$ & .20 \\
\hline Maximum & $-2.80 \pm 3.76$ & .26 & $-1.31 \pm 3.16$ & .18 \\
\hline Minimum-maximum & $1.19 \pm 3.73$ & .38 & $-0.37 \pm 4.6$ & .41 \\
\hline Superior & $-1.52 \pm 2.84$ & .32 & $-1 \pm 2.26$ & .16 \\
\hline Inferior & $-1.71 \pm 2.61$ & .26 & $-0.94 \pm 2.27$ & .19 \\
\hline
\end{tabular}

$X$ and $Y$ coordinates $=$ the thinnest point besides the center of the cornea

*Student $t$ test for within-group comparison

'Statistically significant $(P<.05)$ 
Table 4. Correlations between the variations of topographic and pachymetric parameters.

\begin{tabular}{|c|c|c|c|c|c|c|c|c|c|}
\hline \multirow[b]{2}{*}{ Parameter } & \multicolumn{9}{|c|}{ Parameter } \\
\hline & Kmax & SimKmax & ElevAnt & SimKAstig & SimKmin & MeanPwr3-5 & СCT & TCT & CET \\
\hline Kmax & - & - & - & - & - & - & - & - & - \\
\hline \multicolumn{10}{|l|}{ SimKmax } \\
\hline r value & 0.66 & - & - & - & - & - & - & - & - \\
\hline$P$ value & .001 & - & - & - & - & - & - & - & - \\
\hline \multicolumn{10}{|l|}{ ElevAnt } \\
\hline rvalue & -0.51 & -0.60 & - & - & - & - & - & - & - \\
\hline$P$ value & $<.001$ & $<.001$ & - & - & - & - & - & - & - \\
\hline \multicolumn{10}{|l|}{ SimKAstig } \\
\hline rvalue & 0.44 & 0.31 & -0.25 & - & - & - & - & - & - \\
\hline$P$ value & $<.001$ & .001 & .001 & - & - & - & - & - & - \\
\hline \multicolumn{10}{|l|}{ SimKmin } \\
\hline$r$ value & 0.47 & 0.64 & -0.58 & -0.08 & - & - & - & - & - \\
\hline$P$ value & $<.001$ & $<.001$ & $<.001$ & .438 & - & - & - & - & - \\
\hline \multicolumn{10}{|l|}{ MeanPwr3-5 } \\
\hline rvalue & 0.60 & 0.77 & -0.69 & 0.23 & 0.70 & - & - & - & - \\
\hline$P$ value & $<.001$ & $<.001$ & $<.001$ & .026 & $<.001$ & - & - & - & - \\
\hline \multicolumn{10}{|l|}{ CCT } \\
\hline rvalue & -0.47 & -0.50 & 0.47 & -0.14 & -0.44 & -0.56 & - & - & - \\
\hline$P$ value & $<.001$ & $<.001$ & $<.001$ & .155 & $<.001$ & $<.001$ & - & - & - \\
\hline \multicolumn{10}{|l|}{ TCT } \\
\hline$r$ value & -0.61 & -0.56 & 0.57 & -0.30 & -0.42 & -0.67 & 0.60 & - & - \\
\hline$P$ value & $<.001$ & $<.001$ & $<.001$ & .002 & $<.001$ & $<.001$ & $<.001$ & - & - \\
\hline CET & & & & & & & & - & - \\
\hline$r$ value & -0.28 & -0.21 & 0.17 & 0.03 & -0.27 & -0.18 & 0.18 & 0.12 & - \\
\hline$P$ value & .003 & .029 & .078 & .769 & .006 & .081 & .086 & .218 & - \\
\hline \multicolumn{10}{|l|}{ TET } \\
\hline rvalue & -0.21 & -0.11 & 0.005 & -0.06 & -0.10 & -0.12 & 0.12 & 0.22 & 0.28 \\
\hline$P$ value ${ }^{*}$ & .041 & .270 & .957 & .564 & .324 & .279 & .267 & .022 & .00 \\
\hline
\end{tabular}

$\mathrm{CCT}=$ central corneal thickness; CET = central epithelial thickness; ElevAnt = anterior elevation; Kmax = maximum keratometry; MeanPwr3-5 = mean corneal power in paracentral 3-5 mm; SimKAstig = simulated astigmatism; SimKmax = simulated maximum keratometry; SimKmin = simulated minimum keratometry; TCT $=$ thinnest corneal thickness; TET $=$ thinnest epithelial thickness

${ }^{*}$ Statistically significant $(P<.05$; Spearman correlation test $)$

(keratoconus progression was defined as an increase of at least $1.0 \mathrm{D}$ in the steepest $\mathrm{K}$ measurement over a period of 6 months). The optimum cutoff point for distinguishing

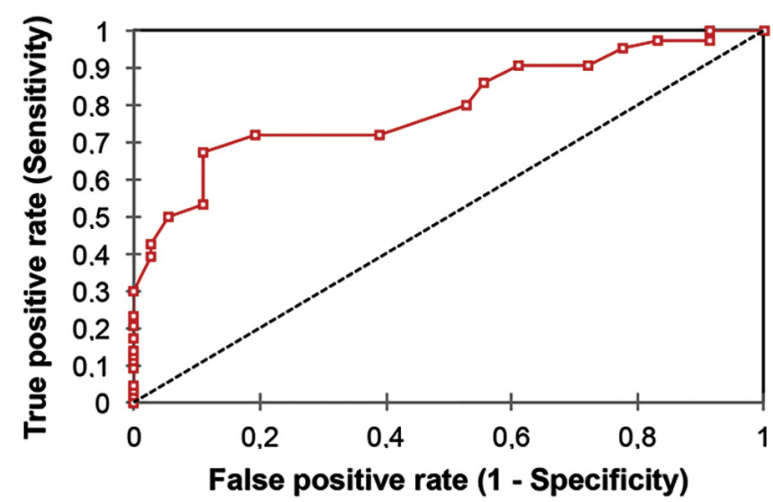

Figure 1. The receiver operating characteristic curve for the change in thinnest corneal thickness with optical coherence tomography. The optimum cutoff point for distinguishing between keratoconus progress and stable keratoconus was identified as $-5 \mu \mathrm{m}$. This threshold value was associated with a sensitivity of $68 \%$ and a specificity of $89 \%$ for the diagnosis of keratoconus progression; change in TCT/AUC $=0.79$ (AUC $=$ area under the curve; TCT $=$ thinnest corneal thickness). between keratoconus progress and stable keratoconus was identified as $-5 \mu \mathrm{m}$. This threshold value was associated with a sensitivity of $68 \%$ and a specificity of $89 \%$ for the diagnosis of keratoconus progression, with AUC at 0.79 .

The ROC curves were plotted for CCT (sensitivity of $46 \%$, specificity of $94 \%$ with a cutoff value at $-7 \mu \mathrm{m}$ ), central epithelial thickness (sensitivity of $15 \%$, specificity of $97 \%$ with a cutoff value at $-5 \mu \mathrm{m}$ ), and thinnest epithelial thickness (sensitivity of $17 \%$ and a specificity of $97 \%$ with a cutoff value at $-5 \mu \mathrm{m}$ ), and had lower performances for the positive diagnosis of keratoconus progression.

\section{DISCUSSION}

Keratoconus is a noninflammatory disease characterized by progressive corneal thinning and apical protrusion. Several studies have tried to define models for the prediction of keratoconus progression. Choi et al. ${ }^{25}$ used several topographic analyses to document the disease progression. Ahn et al. ${ }^{26}$ tracked the longitudinal changes in the topographic findings of keratoconus up to keratoplasty and suggest a criterion for the keratoconus progression taken from diverse topographic indices of the Orbscan IIz scanning-slit corneal topographer. Kanellopoulos et al. ${ }^{27}$ recommend using the 
index of surface variance and the index of height decentration to diagnose the progression of keratoconus.

No corneal thinning threshold for disease progression has yet been defined. In this study, we observed thinning of the corneal central and minimum thickness in cases of progressive keratoconus. We found that changes in maximum $\mathrm{K}$ were strongly correlated with corneal and epithelial thinning in the central and thinnest areas.

Indeed, in histologic studies, a decrease in the number of collagen lamellae in keratoconus and excessive stromal degradation have been shown to occur, inducing an increase in proteolytic activity. ${ }^{28,29}$ According to Sykakis et al., ${ }^{30}$ there is a correlation between stromal thinning and the number of breaks in the Descemet layer. During 6 years of follow-up of keratoconus cases, $18 \%$ of which were progressive, Fujimoto et al. ${ }^{31}$ noted significant thinning of the thinnest cornea measured by anterior segment swept-source OCT each year. However, there was no comparative analysis of progressive cases and nonprogressive cases of keratoconus.

There was significant epithelial thinning at the thinnest point in cases of progressive keratoconus. In this keratoconus, the basal epithelial cells are irregularly arranged, there is a decrease in cell density, and epithelial thickness is negatively correlated with the severity of ectasia in the early stage of the disease. ${ }^{4,32,33}$ Furthermore, it has been suggested that there is a correlation between the number of breaks in Descemet layer and the epithelial thickness. ${ }^{34}$ In vivo epithelial mapping analysis is a recent development. Using Fourierdomain OCT, Rocha et al. ${ }^{32}$ found thinning of the epithelium at the vertex surrounded by a thickened circle in areas of lesser anterior elevation. This doughnut-shape modification might reflect a tendency of the epithelium to regulate the corneal surface. ${ }^{33,34}$

Current elevation topography analyzes the anterior and posterior sides of the cornea, comparing them with a best-fit sphere calculated from the raw elevation data such that the radius selected corresponds to the best fit to the corneal surface. According to Belin et al., ${ }^{35}$ in corneas with pathology, corneal deformation distorts the best-fit sphere, minimizing the elevation data. Corneal topography analyses provide no information about structural modifications in progressive keratoconus. ${ }^{36}$ Schlegel et al. ${ }^{37}$ showed that visible anomalies on curvature maps were preceded by modifications of the posterior elevation. Thus, topographic modifications are delayed when keratoconus progresses. Because maximum $\mathrm{K}$ is the steepest anterior corneal curvature from a central area, ${ }^{38}$ it cannot not be used to diagnose the progression of ectasia involving the posterior face of the cornea. ${ }^{39}$ Progressive posterior ectasia must include thinning at the thinnest point. ${ }^{40}$ Interestingly, Grieve et al., ${ }^{41}$ in their analysis of pathological corneal lenticules, showed that in vitro Fourier-domain OCT (axial resolution $1 \mu \mathrm{m}$ ) provided results representative of the histological reality for the cornea.

We evaluated the precision of measurements obtained with RTVue Fourier-domain OCT device and the Orbscan $\mathrm{IIz}$ scanning-slit corneal topographer. The mean interobserver variation of maximum $\mathrm{K}$ measurement was $0.3 \mathrm{D}$. This value is close to that reported by Hashemi et al. ${ }^{17}$ for keratoconus; they found maximum $\mathrm{K}$ values between $50.0 \mathrm{D}$ and $55.0 \mathrm{D}$, which is much lower than the value reported by Guilbert et al. ${ }^{16}$ for AmslerKrumeich stage 1 and 2 keratoconus and for all stage scombined. The mean interobserver variation was $4.8 \mu \mathrm{m}$ for the thinnest corneal thickness and $1.8 \mu \mathrm{m}$ for the thinnest epithelial thickness. These values are similar to those reported by $\mathrm{Li}$ et al. $^{34}(3.9 \mu \mathrm{m}$ and $1.8 \mu \mathrm{m}$, respectively). We used the repeatability thresholds of the scanning-slit corneal topographer maximum $\mathrm{K}$ measurements and Fourier-domain OCT corneal and epithelial minimum thicknesses to establish the sensitivity and specificity of the variation of each parameter for the diagnosis of keratoconus progression. A comparison of patients with and without significant changes in thinnest corneal thickness showed that this parameter changed in the most progressive cases of keratoconus. The other measurements (CCT, central epithelial thickness, thinnest epithelial thicknesses) had lower performances in terms of diagnosing keratoconus progression.

We attempted to define values for thinning of the epithelium and cornea that could be used to diagnose the progression of ectasia. Given the repeatability of OCT measurements, $5 \mu \mathrm{m}$ thinning of the thinnest corneal thickness between 2 consecutive tests was found to have a sensitivity of $68 \%$ and a specificity of $89 \%$ for the diagnosis of disease progression.

The $89 \%$ specificity of a $5 \mu \mathrm{m}$ decrease in thinnest corneal thickness is good to distinguish progressive keratoconus. However, $68 \%$ sensitivity is quite low. Values might have been more explicit if we had studied keratoconus with more posterior steepening and more thinning. However, it would have not been ethical; indeed, CXL was performed when the maximum $\mathrm{K}$ value increased by $1.0 \mathrm{D}$, according to the established criteria. Finally, our purpose was not to define $5 \mu \mathrm{m}$ of thinning at the thinnest cornea area as an absolute and exclusive value for the ectatic progression; however, we suggest taking it into account in addition to increases in $\mathrm{K}$ measurements.

In the absence of consensus criteria, we defined progressive cases as those in which the increase in maximum $K$ was at least $1.0 \mathrm{D}$ over 6 months. Maximum $\mathrm{K}$ is the most commonly used parameter to detect or document ectatic progression. We chose the value of $1.0 \mathrm{D}$ over 6 months because it has been suggested by several authors studying the efficiency of CXL. ${ }^{9-13,42,43}$ Few authors chose corneal thinning to define the progression of the disease, and no consistent value has been quoted. ${ }^{44,45}$ Because we wanted to evaluate corneal thinning to define the progression of the disease, it was not rational to define the groups with this measure. Moreover, in the progressive keratoconus group, the mean maximum $\mathrm{K}$ increased to $2.1 \mathrm{D}$ during follow-up, indicating that these cases were clearly progressive. Furthermore, the increase in maximum $\mathrm{K}$ was correlated with other topographic data, such as anterior elevation, simulated maximum $\mathrm{K}$, mean power, and 
simulated astigmatism in the paracentral 3.0 to $5.0 \mathrm{~mm}$, suggesting that the groups identified in this study were pertinent. $^{26}$

The mean follow-up in our study was 8.4 months. All patients diagnosed with progressive keratoconus had CXL treatment. A longer follow-up for corneal and epithelial mapping for progressive keratoconus would have been interesting but would also have been unethical and was therefore not performed.

The patients in our study population had grade I or II keratoconus on the Sandali classification. ${ }^{4}$ Patients with advanced keratoconus who had lost corneal transparency and had major corneal thinning were not included. Our final objective was to evaluate the use of corneal mapping to determine whether CXL was appropriate. We did not, therefore, consider the absence of advanced keratoconus cases to be a major limitation.

Topographic data do not reflect the structural changes occurring during the aggravation of ectasia. Based on pachymetric parameters measured by Fourier-domain OCT, we showed that corneal thinning and epithelial thinning were correlated with corneal deformation. The use of Fourier-domain OCT for the follow-up of keratoconus appears to be indicated even in the absence of topographic progression criteria. Corneal thinning at the thinnest part of the cornea was found to be a particularly strong marker of evolution.

To conclude, high-resolution Fourier-domain OCT was useful for accurate corneal mapping. Consistent with pathology findings, corneal thinning at the thinnest part of the cornea was found to be a particularly good marker for assessing disease progression. Given the imprecision of topographic measurements, in particular in abnormal corneas, corneal thinning seems to be a very pertinent parameter for determining whether CXL is appropriate and should therefore be included in the routine examinations during the follow-up of keratoconus patients.

\section{WHAT WAS KNOWN}

- Keratoconus is characterized by progressive corneal thinning and apical protrusion.

- No corneal thinning threshold for disease progression has been defined.

\section{WHAT THIS PAPER ADDS}

- New anatomic criteria were established based on corneal OCT for progressive keratoconus.

- Maximum K was strongly positively correlated with corneal and epithelial thinning in the central and thinnest areas.

- A $5 \mu \mathrm{m}$ thinning thinnest area of the cornea had a sensitivity of $68 \%$ and a specificity of $89 \%$ for the diagnosis of disease progression.

\section{REFERENCES}

1. Godefrooij DA, de Wit GA, Uiterwaal CS, Imhof SM, Wisse RPL. Age-specific incidence and prevalence of keratoconus: a nationwide registration study. Am J Ophthalmol 2017; 175:169-172
2. Rabinowitz YS. Keratoconus. Surv Ophthalmol 1998; 42:297-319

3. Krachmer JH, Feder RS, Belin MW. Keratoconus and related noninflammatory corneal thinning disorders. Surv Ophthalmol 1984; 28:293-322

4. Sandali O, El Sanharawi M, Temstet C, Hamiche T, Galan A, Ghouali W, Goemaere I, Basli E, Borderie V, Laroche L. Fourier-domain optical coherence tomography imaging in keratoconus; a corneal structural classification. Ophthalmology 2013; 120:2403-2412

5. Zadnik K, Barr JT, Gordon MO. Edrington TB for the Collaborative Longitudinal Evaluation of Keratoconus (CLEK) Study Group. Biomicroscopic signs and disease severity in keratoconus. Cornea 1996; 15:139-146

6. Meiri Z, Keren S, Rosenblatt A, Sarig T, Shenhav L, Varssano D. Efficacy of corneal cross-linking for the treatment of keratoconus: a systematic review and meta-analysis. Cornea 2016; 35:417-428

7. Godefrooij DA, Gans R, Imhof SM, Wisse RPL. Nationwide reduction in the number of corneal transplantations for keratoconus following the implementation of cross-linking. Acta Ophthalmol 2016; 94:675-678

8. Greenstein SA, Fry KL, Hersh PS. Corneal topography indices after corneal collagen crosslinking for keratoconus and corneal ectasia: one-year results. J Cataract Refract Surg 2011; 37:1282-1290

9. Bouheraoua N, Jouve L, El Sanharawi M, Sandali O, Temstet C, Loriaut P Basli E, Borderie V, Laroche L. Optical coherence tomography and confocal microscopy following three different protocols of corneal collagen-crosslinking in keratoconus. Invest Ophthalmol Vis Sci 2014 55:7601-7609

10. Raiskup-Wolf F, Hoyer A, Spoerl E, Pillunat LE. Collagen crosslinking with riboflavin and ultraviolet-A light in keratoconus: long-term results. J Cataract Refract Surg 2008; 34:796-801

11. Asri D, Touboul D, Fournié P, Malet F, Garra C, Gallois A, Malecaze F. Colin J. Corneal collagen crosslinking in progressive keratoconus: multicenter results from the French National Reference Center for Keratoconus. J Cataract Refract Surg 2011; 37:2137-2143

12. Hashemi H, Miraftab M, Seyedian MA, Hafezi F, Bahrmandy H, Heidarian S, Amanzadeh K, Nikbin H, Fotouhi A, Asgari S. Long-term results of an accelerated corneal cross-linking protocol $\left(18 \mathrm{~mW} / \mathrm{cm}^{2}\right)$ for the treatment of progressive keratoconus. Am J Ophthalmol 2015; 160:1164-1170

13. Lang SJ, Messmer EM, Geerling G, Mackert MJ, Brunner T, Dollak S Kutchoukov B, Böhringer D, Reinhard T, Maier P. Prospective, randomized, double-blind trial to investigate the efficacy and safety of corneal crosslinking to halt the progression of keratoconus. BMC Ophthalmol 2015; 15:78

14. Gomes JAP, Tan D, Rapuano CJ, Belin MW, Ambrósio R Jr, Guell JL, Malecaze F, Nishida K, Sangwan VS. the Group of Panelists for the Global Delphi Panel of Keratoconus and Ectatic Diseases. Global consensus on keratoconus and ectatic diseases. Cornea 2015; 34:359-369

15. Meyer JJ, Gokul A, Vellara HR, Prime Z, McGhee CNJ. Repeatability and agreement of Orbscan II, Pentacam HR, and Galilei tomography systems in corneas with keratoconus. Am J Ophthalmol 2017; 175:122-128

16. Guilbert E, Saad A, Elluard M, Grise-Dulac A, Rouger H, Gatinel D. Repeatability of keratometry measurements obtained with three topographers in keratoconic and normal corneas. J Refract Surg 2016; 32:187-192

17. Hashemi H, Yekta A, Khabazkhoob M. Effect of keratoconus grades on repeatability of keratometry readings: comparison of 5 devices. J Cataract Refract Surg 2015; 41:1065-1072

18. Asgari S, Hashemi H, Jafarzadehpur E, Mohamadi A, Rezvan F, Fotouhi A OPD-Scan III: a repeatability and inter-device agreement study of a multifunctional device in emmetropia, ametropia, and keratoconus. Int Ophthalmol 2016; 36:697-705

19. Crawford AZ, Patel DV, McGhee CNJ. Comparison and repeatability of ker atometric and corneal power measurements obtained by Orbscan II, Pentacam, and Galilei corneal tomography systems. Am J Ophthalmol 2013; 156:53-60

20. Jinabhai A, O'Donnell C, Radhakrishnan H. A comparison between subjective refraction and aberrometry-derived refraction in keratoconus patients and control subjects. Curr Eye Res 2010; 35:703-714

21. Davis LJ, Schechtman KB, Begley CG, Shin JA, Zadnik K, the CLEK Study Group. Repeatability of refraction and corrected visual acuity in keratoconus. Optom Vis Sci 1998; 75:887-896

22. Krumeich JH, Daniel J. Lebend-Epikeratophakie und Tiefe Lamelläre Keratoplastik zur Stadiengerechten chirurgischen Behandlung des Keratokonus (KK) I-III [Live-epikeratophakia and deep lamellar keratoplasty for stagerelated treatment of keratoconus]. Klin Monatsbl Augenheilkd 1997; 211:94-100

23. U.S. Food and Drug Administration. Medical devices. Contact lenses. Silver Springs, MD, U.S. Food and Drug Administration, 2018

24. Hashemi H, Firoozabadi MR, Mehravaranb S, Gorouhi F. Corneal stability after discontinued soft contact lens wear. Cont Lens Anterior Eye 2008; $31: 122-125$ 
25. Choi JA, Kim M-S. Progression of keratoconus by longitudinal assessment with corneal topography. Invest Ophthalmol Vis Sci 2012; 53:927-935

26. Ahn SJ, Kim MK, Wee WR. Topographic progression of keratoconus in the Korean population. Korean J Ophthalmol 2013; 27:162-166

27. Kanellopoulos AJ, Asimellis G. Anterior segment optical coherence tomography: Assisted topographic corneal epithelial thickness distribution imaging of a keratoconus patient. Case Rep Ophthalmol 2013; 4:74-78

28. Bitirgen G, Ozkagnici A, Bozkurt B, Malik RA. In vivo corneal confocal microscopic analysis in patients with keratoconus. Int J Ophthalmol 2015; 8:534539

29. Yadav R, Kottaiyan R, Ahmad K, Yoon G. Epithelium and Bowman's layer thickness and light scatter in keratoconic cornea evaluated using ultrahigh resolution optical coherence tomography. J Biomed Opt 2012; 17:116010

30. Sykakis E, Carley F, Irion L, Denton J, Hillarby MC. An in depth analysis of histopathological characteristics found in keratoconus. Pathology 2012 44:234-239

31. Fujimoto H, Maeda N, Shintani A, Nakagawa T, Fuchihata M, Higashiura R, Nishida K. Quantitative evaluation of the natural progression of keratoconus using three-dimensional optical coherence tomography. Invest Ophthalmo Vis Sci 2016; 57:169-175

32. Rocha KM, Perez-Straziota CE, Stulting RD, Randleman JB. SD-OCT analysis of regional epithelial thickness profiles in keratoconus, postoperative corneal ectasia, and normal eyes. J Refract Surg 2013; 29:173-179; errata, 234

33. Reinstein DZ, Archer TJ, Gobbe M. Corneal epithelial thickness profile in the diagnosis of keratoconus. J Refract Surg 2009; 25:604-610

34. LiY, Tan O, Brass R, Weiss JL, Huang D. Corneal epithelial thickness mapping by Fourier-domain optical coherence tomography in normal and keratoconic eyes. Ophthalmology 2012; 119:2425-2433

35. Belin MW, Villavicencio OF, Ambrósio RR Jr. Tomographic parameters for the detection of keratoconus: suggestions for screening and treatment parameters. Eye Contact Lens 2014: 40:326-330

36. Rao SN, Raviv T, Majmudar PA, Epstein RJ. Role of Orbscan II in screening keratoconus suspects before refractive corneal surgery. Ophthalmology 2002; 109:1642-1646

37. Schlegel Z, Hoang-Xuan T, Gatinel D. Comparison of and correlation between anterior and posterior corneal elevation maps in normal eyes and keratoconus-suspect eyes. J Cataract Refract Surg 2008; 34:789-795
38. Epstein RL, Chiu Y-L, Epstein GL. Pentacam HR criteria for curvature change in keratoconus and postoperative LASIK ectasia. J Refract Surg 2012; 28:890-894

39. Tomidokoro A, Oshika T, Amano S, Higaki S, Maeda N, Miyata K. Changes in anterior and posterior corneal curvatures in keratoconus. Ophthalmology 2000; 107:1328-1332

40. Duncan JK, Belin MW, Borgstrom M. Assessing progression of keratoconus: novel tomographic determinants. Eye Vis 2016; 3:6

41. Grieve K, Georgeon C, Andreiuolo F, Borderie M, Ghoubay D, Rault J, Borderie VM. Imaging microscopic features of keratoconic corneal morphology. Cornea 2016; 35:1621-1630

42. Wittig-Silva C, Chan E, Islam FMA, Wu T, Whiting M, Snibson GR. A randomized, controlled trial of corneal collagen cross-linking in progressive keratoconus; three-year results. Ophthalmology 2014; 121:812-821

43. Wollensak G. Crosslinking treatment of progressive keratoconus: new hope. Curr Opin Ophtalmol 2006; 17:356-360

44. Vinciguerra P, Albè E, Trazza S, Rosetta P, Vinciguerra R, Seiler T, Epstein D. Refractive, topographic, tomographic, and aberrometric analysis of keratoconic eyes undergoing corneal cross-linking. Ophthalmology 2009; 116:369-378

45. Chatzis N, Hafezi F. Progression of keratoconus and efficacy of pediatric corneal collagen cross-linking in children and adolescents. J Refract Surg 2012; 28:753-758; errata 2013; 29:72

Disclosures: None of the authors has a financial or proprietary interest in any material or method mentioned.

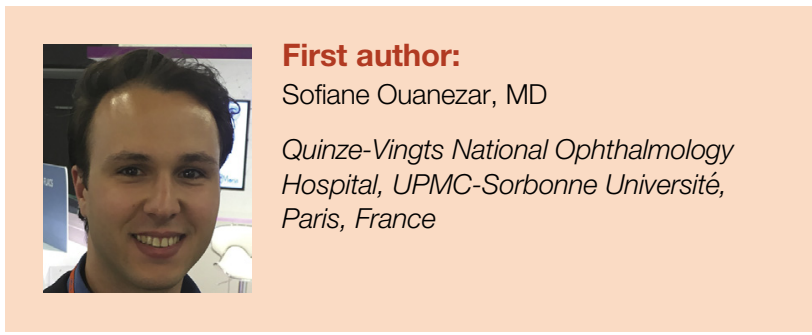

